Элькан О. Б.

O. B. Elkan

ВЕРБАЛИЗАЦИЯ И ВИЗУАЛИЗАЦИЯ МУЗЫКАЛЬНОГО ТЕКСТА В МУЗЫКАЛЬНОЙ

РИТОРИКЕ И. С. БАХА

\title{
MUSIC TEXT VERBALIZATION AND VISUALIZATION IN THE MUSIC RHETORIC OF J. S BACH
}

Элькан Ольга Борисовна - кандидат культурологии, проректор по научной работе Крымского университета культуры, искусств и туризма (Россия, Республика Крым, Симферополь); 295017, Симферополь, ул. Киевская, 39; тел. 8(3652)276458. E-mail: elkanolga@gmail.com.

Ms. Olga B. Elkan - PhD in Culture Studies, Vice-Rector for Research Work, Crimean University of Culture, Arts and Tourism (Russia, Republic of Crimea, Simferopol); 295017, Simferopol, Kievskaya st., 39; tel. 8(3652)276458. E-mail: elkanolga@gmail.com.

Аннотация. Актуальность избранной темы обусловлена обращением к проблемам специфики явлений, которые находятся в орбите современных исследований теории и истории культуры: синтетичность феноменов культуры, кросскультурные взаимодействия, социокультурная и культурно-историческая детерминация ее процессов и механизмов на каждом конкретном этапе общественного развития, соотношение формы и содержания, традиций и новаторства и т.п. Писатель ХХ в. Герман Гессе, чьим пристрастием с ранних лет было музыкальное наследие эпохи барокко, пронизывает свой роман «Игра в бисер» музыкой И. С. Баха. Данный литературно-музыкальный эксперимент обусловлен глубоким знанием Гессе биографии и творчества немецкого композитора, склонного к подобным «играм» - музыкальной символике, в том числе нумерологической, и так называемой «музыкальной риторике», ставившей своей задачей вербализацию музыкальных текстов. Музыка И. С. Баха, возможно, впервые продемонстрировала истинный потенциал «слияния» музыкальной мощи с литературно-поэтической основой, а также «музыкальной живописи», что позволило уже в XIX в. Рихарду Вагнеру облечь общее представление о синестетизме в человеческом восприятии, обращение к катарсису и преображению социального миропорядка в концепт Gesamtkunstwerk, оказавший в дальнейшем влияние на немецкую культуру и получивший развитие в научной теории и художественной практике постромантиков и нововенцев.

Summary. The relevance of the chosen topic is caused by the reference to the problems of the phenomena that are in the focus of modern research of the theory and history of culture. These are the synesthetism of culture phenomena, cross-cultural interaction, socio-cultural and cultural-historical determination of its processes and mechanisms at each stage of social development, the relationship between the form and the content, the tradition and the innovation, etc. The writer of the twentieth century Hermann Hesse, whose passion was musical heritage of the Baroque era from an early age, permeated his novel «The glass bead game» with the music by J. S. Bach. This literary-musical experiment was caused by the deep knowledge of biography and works of the German composer, who was inclined to such «games» as the musical symbolism, including numerology, and the so-called «musical rhetoric», aimed at the verbalization of musical texts. J. S. Bach's music, perhaps for the first time demonstrated the true potential of music power combination with a literary basis, as well as with «musical painting». All that allowed Richard Wagner transform a general idea of synesthetism in human perception already in the nineteenth century, the appeal to catharsis and transformation of the social order in the concept of Gesamtkunstwerk, which further impacted on German culture and developed into the scientific theory and artistic practice of post romantics and the new Viennese school representatives.

Ключевые слова: И. С. Бах, синтез искусств, синестезия, музыка, литература, риторика, вербализация, визуализация, музыкальность, музыкализация.

Key words: J. S. Bach, synthesis of arts, synesthesia, music, literature, rhetoric, verbalization, visualization, musicality, musicalization. 
Элькан О. Б.

ВЕРБАЛИЗАЦИЯ И ВИЗУАЛИЗАЦИЯ МУЗЫКАЛЬНОГО ТЕКСТА В МУЗЫКАЛЬНОЙ РИТОРИКЕ И. С. БАХА

УДК 008:78.01(430)

Стремление к практическому воплощению принципа синестетизма, которое впоследствии послужило основой для формирования и развития концепта Gesamkunstwerk [12], особенно ярко проявилось в так называемой музыкальной риторике и музыкальной символике эпохи барокко; в первую очередь - в творчестве величайшего композитора Иоганна Себастьяна Баха.

Интерес современных исследователей к данной теме обусловлен той значимостью, которую обретает «для искусствознания движение “вглубь" с целью выявления в недрах художественной образности скрытых интрамузыкальных механизмов формирования смыслов» $[3,19]$.

Данная установка, которую можно обозначить словами А. Ф. Лосева как «“поиски мысленной картины живой связи вещей”, в которой “смысловые элементы даны как живое целое"» [5, 429], очень хорошо сформулирована также И. Земцовским: «Текст должен ожить в руках исследователя. Видимое в нем должно открыть нам невидимое» $[2,5]$. Акцент при этом переносится со структурно-функционального либо семантического анализа на обнаружение целостного смыслового поля; некоторые исследователи предполагают даже создание с этой целью новой «синтетической» дисциплины, которую они предлагают назвать «психомузыкознание» $[2,6]$.

Психологическая составляющая подобного поиска обусловливает обращение к формам, «имеющим экспрессивно-эмоциональную окраску и формирующим “чувственную ткань" образа... В частности, данную функцию осуществляют в трудах по музыкальной семантике такие смыслопорождающие коды, как музыкальная эмблематика, риторические фигуры» [3, 21].

Этот подход открывает важность такого элемента музыкального искусства, как музыкально-риторические фигуры. Как известно, музыка XVII и XVIII вв., известная сегодня как музыка барокко, отличается важной особенностью, характерной, впрочем, в целом для всего барочного искусства: высокой степенью орнаментации. В музыке это как раз и достигалось за счет использования музыкально-риторических фигур.

Так называемая «музыкальная риторика», достигшая своего расцвета в эпоху барокко, ставит перед собой задачу своего рода «вербализации» музыкального текста, то есть ту же задачу, которую позднее пытался решать и Вагнер в своей системе лейтмотивов. Такая вербализация должна была придать определенным музыкальным фрагментам статус неких формул с вполне конкретным вербальным содержанием, превратить их в «буквы», «слова» и даже «фразы», передаваемые чисто музыкальными средствами.

Пика своего развития техника музыкальной риторики достигает в семнадцатом веке вместе с признанием доминирующего положения инструментальной музыки. В этот период теоретики и композиторы разрабатывают специальные риторические приемы, призванные установить связь музыкального текста с вербальным выражением. Иоахим Бурмайстер, Кристоф Бернхард и Иоганн Маттезон широко используют кодифицированные музыкально-риторические фигуры в собственной композиторской практике. Кроме того, в семнадцатом веке теоретики, такие как Кирхер, разрабатывали специальные теории музыкальных средств эмоциональной выразительности, известные сегодня под общим названием «теория аффектов», а также риторические принципы мелодического дизайна, гармонии и формы с целью активного использования потенциала риторики в музыкальном искусстве. Для немецких педагогов того периода, преподающих музыку и композицию, было привычным обучать своих студентов использовать музыкальную риторику, способную, как считалось, возбуждать вполне конкретные эмоциональные реакции у слушателей.

Музыкальная риторика развивалась как ответвление «теории аффектов», также весьма популярной в барочной музыке и музыковедении: согласно ей, определенные музыкальные средства должны выражать характерные психологические аффекты, к которым относились, например (в классификации А. Кирхера): tristia («печаль, скорбь»), amor («любовь»), audacio («отвага»), furor («ярость») и др. Каждому «аффекту» соответствуют собственные характеристики - лад, тональность, ритмический рисунок и т.П. «Аффекты барокко достигли своего апогея в творчестве И. С. Баха» $[10,204]$. 


\section{Учёные записки}

Комсомольского-на-Амуре государственного технического университета

Новую волну интереса к этой теме на рубеже XIX и XX вв. в значительной мере инициировал великий немецкий гуманист, лауреат премии Гете и Нобелевской премии Альберт Швейцер.

В 1905 - 1908 гг. издается капитальный труд Швейцера, посвященный творчеству Иоганна Себастьяна Баха. Опираясь на проделанное им скрупулезное исследование баховского наследия, Швейцер, сам признанный и успешно концертирующий органист, приходит к необходимости решения назревшей проблемы «взаимодействия искусств». Обычно, утверждает он, эту проблему принято рассматривать лишь в связи с каким-то конкретным видом искусства, тогда как она представляет собой «наиболее общую проблему», с которой «должно начинаться всякое размышление об искусстве» $[11,323]$.

Наша ошибка, по мнению Швейцера, заключается в том, что мы привыкли разделять искусство на отдельные виды в зависимости от того, какие выразительные средства использует мастер для художественного отображения мира, в котором он живет: музыкант использует звуки, художник - краски, поэт - слово, но все это - «чисто внешнее отличие», «нечто второстепенное». В действительности каждый творец, полагает Швейцер, сочетает в себе и музыканта, и художника, и поэта, поскольку всякое творчество в сфере искусства «основано на их взаимодействии» $[11,323]$.

Одна из центральных по значению глав работы Швейцера так и называется - «Поэтическая и живописная музыка», и здесь он выходит уже далеко за рамки одного только баховского творчества. Как в музыке Баха и Вагнера он видит поэзию, так и в поэзии Гете, Гейне - словесную живопись, в поэзии Готфрида Келлера - драматическое искусство, в поэзии Шиллера - музыку, в литературных произведениях Ницше - симфонии.

Воплощению данного принципа конкретно в творчестве Баха посвящен очень объемный раздел книги Швейцера «Слово и звук у Баха». «Трудно представить себе более живую, тесную связь музыки с текстом, чем в произведениях Баха, - замечает Швейцер. - Это бросается в глаза даже при поверхностном знакомстве с ними: обнаруживается не только большее или меньшее соответствие между фразой словесной и музыкальной - их структуры тождественны!..» [11, 337]. «Поэтичность» музыки Баха (в смысле ее максимального соответствия тексту) и ее «живописность» (изобразительная мощь) достигают настолько высокого уровня, что это даже заставило Швейцера воскликнуть: «Он осмелился переступить естественные границы звукового искусства» $[11,359]$.

Рассмотрим несколько подробней баховскую музыкальную риторику. «... всякий язык, пишет Швейцер, - существует лишь благодаря соглашению, в силу которого известные соединения звуков соответствуют тем или иным мыслям или представлениям [...] Кто знаком с языком композитора и знает, какие образы он выражает определенными сочетаниями звуков, тот услышит в пьесе мысли, которые непосвященный не обнаружит, несмотря на то что эти образы заключены в ней» $[11,331]$.

Швейцер, с привлечением огромного массива баховских материалов, подвергает детальному рассмотрению музыкальные средства, в том числе музыкально-риторические фигуры, используемые Бахом для выражения в своих произведениях самых различных мотивов («мотив шага», «мотивы блаженного покоя», «мотивы скорби», «мотив тревоги», «мотив испуга» и т.п. - даже простое их перечисление заняло бы здесь слишком много места). Например, «... для выражения радости у Баха есть две формулы. Он передает ее то последовательностью восьмых или шестнадцатых по ступеням гаммы, то многократным повторением ритмической формулы восьмая - две шестнадцатых [11,367].

«С легкой руки» Швейцера эта тема становится весьма востребованной в работах современных музыковедов. Возможно, «код Баха» еще не столь популярен в массовой культуре, как (стараниями Дэна Брауна) «код да Винчи», но в профессиональных кругах «число работ, посвященных символике в музыке Баха либо затрагивающих эту проблему более или менее подробно, чрезвычайно велико и с каждым годом все возрастает. Наиболее серьезные работы по рассматриваемой проблеме - это труды Фридриха Сменда, [...] работы Р. Ливера, Э. Бергеля, В. Бланкенбурга, Ф. Букофцера, Р. Керри» и др. $[1,325]$. Серьезный вклад в разработку проблемы внесли и отечественные исследователи, в первую очередь видный советский теоретик музыки, пианист и 
Элькан О. Б.

ВЕРБАЛИЗАЦИЯ И ВИЗУАЛИЗАЦИЯ МУЗЫКАЛЬНОГО ТЕКСТА В МУЗЫКАЛЬНОЙ РИТОРИКЕ И. С. БАХА

композитор Б. Л. Яворский, еще в первые десятилетия XX в. в результате многолетних изысканий скрупулезно собравший огромный фактический материал и выделивший несколько десятков мотивных структур в баховской музыке [13].

Результаты исследований Яворского до сих пор не были опубликованы полностью, но сохранились в архивах и послужили дальнейшему развитию исследований темы в работах таких ученых, как В. Б. Носина (на сегодня самый авторитетный в России эксперт по проблеме баховского символизма), М. Друскин, Л. Ф. Семеренко. О. Захарова, Ю. Петров.

Традиционно музыкальная риторика была особенно тесно связана с искусством фуги. Считалось, что использование музыкально-риторических фигур и мотивной символики позволяло автору, ориентируясь на строгие и четкие алгоритмы композиционного построения фуги, в то же время сформировать фугу в убедительной и последовательной форме даже из самой простой темы. Так, китайский музыковед В. Ч. Ляо в своем исследовании прослеживает последовательное воплощение данного принципа на материале четырех фуг И. С. Баха [14].

«...современниками Баха его музыка читалась как понятная речь, ее смысл проявлялся в устойчивых мелодических оборотах, связанных с выражением душевных движений, или с мелодиями и текстами протестантских хоралов и через них - с мыслями, образами и сюжетами Священного Писания. Для слушателей времени Баха его инструментальные сочинения представали не как произведения “чистой” музыки, они были наполнены конкретным образным, психологическим и философско-религиозным содержанием...» $[8,14]$.

Мотивная символика («характерные повторяющиеся мелодические ячейки, которые присутствуют во всех сочинениях Баха, сохраняя закрепленное за ними значение», «определенные мотивные структуры, имеющие постоянное соответствие с определенными вербальными понятиями» $[8,11])$ - настоящий ключ к глубокому пониманию творчества Баха. Перечислим лишь самый минимум из множества музыкально-риторических фигур, традиционно присутствующих во всем творчестве Баха:

- восходящие звукоряды (anabasis) - выражают радость, ликование, экстаз, благоговение;

- нисходящие звукоряды (catabasis) - символы скорби, печали, умирания, положения во гроб;

- восходящее и нисходящее трезвучие как символ предопределения и т.д.

Наиболее популярен среди всех баховских «фигур» так называемый «БАХ-мотив» (das $B A C H$-Motiv), «звуковая расшифровка фамилии Баха - ВАCH» $[8,30]$. Он представляет «один из весьма распространенных в Германии XVII - XVIII столетий способов шифровки в музыке - нотную криптографию, в которой инструментом шифровки служили ноты, а коды для них были самые разные. Один из них, самый простой и естественный...» $[11,353]$, связан с системой буквенного обозначения нот: ля $-A$, си ${ }^{\mathrm{b}}-B, c u-H$, до $-C$, ре $-D$, ми $-E$, фа $-F$, соль $-G$. Таким образом, «БАХ-мотив» состоит из 4 нот: си ${ }^{\mathrm{b}}$ ля до си.

«Уже в Веймаре он указал своему коллеге Вальтеру на особенность четырех букв своей фамилии, объясняя этим музыкальность всех Бахов» $[11,314]$, семьи, подарившей миру более пятидесяти музыкантов и композиторов за два столетия. Данный мотив буквально пронизывает наследие Баха. И этот же мотив, посвящая его великому Баху, позднее использовали в своих сочинениях сотни композиторов, в их числе Шуман, Лист, Брамс, Римский-Корсаков, Пуленк, Шёнберг, Веберн и др.

Еще одна излюбленная баховская фигура - «крест». «Символ креста $[\ldots]$ имеет множество вариантов начертания, но постоянным всегда остается направление тонов [...], которое представляет собой последовательность четырех звуков, ассоциирующуюся с этим символом [...] в связи с числом 4 как символом креста - четырьмя сторонами, вершинами и плоскостями креста» [6, 371].

Отметим, что четыре элемента «музыкальной монограммы» Баха $-B$ - $A$ - $C-H$ - образуют одновременно и фигуру креста.

В одном из писем Б. ЈI. Яворского С. В. Протопопову, написанном в 1917 г., приводится целая развернутая система «расшифрованных» автором баховских музыкально-риторических символов, например: 


\section{Учёные записки}

Комсомольского-на-Амуре государственного технического университета

«1. Равномерное движение нижнего голоса уподоблялось шаганию - такое движение, разумеется, было скорее шагов человека, но невозможно в музыке подражать шагу во времени - это заняло бы слишком много времени; в искусстве всякие житейские явления проецируются на наше сознание, а не фактически копируются.

2. Быстрые восходящие и нисходящие движения выражали полет ангелов, основываясь на словах Нового Завета, когда в рождественскую ночь пастухи увидели реющих с неба на землю и обратно ангелов в сиянии.

3. Короткие, быстрые, размашистые обрывающиеся фигуры изображали ликование.

4. Такие же, но не слишком быстрые фигуры - спокойное довольство...

5. Пунктирный ритм изображал бодрость, величие, торжество.

6. Триольный ритм - усталость, уныние.

7. Скачки вниз на большие интервалы - септимы, ноны - старческую немощь (...). Октава же считалась признаком спокойствия, благополучия, объятия вокруг.

8. Ровный хроматизм из 5-7 звуков - острую печаль, боль (и вверх, и вниз)...

9. Спускающиеся движения по два звука - тихую печаль, достойное горе... тембре.

10. Трелеподобное движение - веселие, даже смех, хохот при соответствующем регистре и

11. Страдания распятого Христа (уменьшенная кварта, несопряжение из гармонического вида двойной системы), обратно - свершение; тот же мотив с синкопой - требование распятия...» $[7,25-27])$ и т.д.

Музыкальная риторика Баха не только придала новый импульс общему развитию музыкальной символики в современный ему период, но и в значительной степени повлияла также и на все ее дальнейшее развитие. Особо популярным в течение веков оставался и остается главный баховский музыкальный символ - его «музыкальная монограмма», или «БАХ-мотив». Специальное обращение к этой музыкально-риторической фигуре у всех композиторов традиционно означало именно выражение почтения и признательности величайшему из них.

Неоднократно отмечается его использование, в частности, в произведениях композиторов Новой венской школы. Так, например, Арнольд Шёнберг использует его в «Вариациях для оркестра» (1926-1928, ор. 31) и Сюите для фортепиано (1921-23, ор. 25).

Тот же мотив использовал ученик и последователь Шёнберга, «сооснователь» Новой венской школы Антон Веберн в Струнном квартете (1936-1938, ор. 28).

Однако в рамках творчества самого Баха стремление к культурному синтезу, к использованию в единой системе как музыкальных, так и внемузыкальных средств выразительности, обеспечивающему тотальность восприятия музыкального текста, далеко не ограничивается музыкальнориторическими фигурами, пусть даже очень многочисленными и многообразными. Сегодня принято даже говорить о «тайнописи» Баха, включая гематрию (числовую символику) его произведений, которой также посвящено уже немало работ. Известно, например, какое огромное значение играет в них цифра 14 - нумерологическое выражение его имени: «Бах, конечно, знал о своем числе $14(B A C H)$ и о его чудесном свойстве обращаться в результате прибавления инициалов -41 (I. S. BACH). Полное написание двух имен и фамилии композитора выражается числом 158 , сумма цифр которого равна $14 ! . . »[9,9])$ - и т.д. Современными исследователями число 14 в нотном тексте баховских произведений трактуется как «речь» самого И. С. Баха, например, прославление музыкантом Господа Бога.

Здесь уместно отметить также участие Баха в так называемом «Обществе музыкальных наук» (Societät der musikalischen Wissenschaften), «усердием которого утверждается совершенствование музыки через математику и философию» [9, 34], созданном в 1738 г. его учеником и другом Лоренцем Мицлером. Бах вступил в него в 1747 г.; почетным его членом был также Гендель. Некоторые характерные особенности Общества и некоторые пункты его устава слишком сильно напоминают аналогичные особенности Ордена игроков в бисер из романа Гессе, чтобы этим сходством мы могли пренебречь. Например, «статьи устава о повышении престижа старинной музыки», в особенности параграф XXV, побуждавший членов общества к возрождению ее величия. 
Элькан О. Б.

ВЕРБАЛИЗАЦИЯ И ВИЗУАЛИЗАЦИЯ МУЗЫКАЛЬНОГО ТЕКСТА В МУЗЫКАЛЬНОЙ РИТОРИКЕ И. С. БАХА

Здесь проявилось полное совпадение с генеральной тенденцией баховских интересов, наметившейся в конце жизненного пути композитора - глубокое изучение манеры старых мастеров Палестрины и Фрескобальди и эволюция полифонического стиля, членство в Обществе музыкальных наук, где пропагандировалось особое внимание к математике и ее связям с музыкой и символикой.

Не все ученые согласны с тем, что Бах всерьез разделял «пифагорейские» воззрения Мицлера. По мнению Швейцера, Бах был «так равнодушен к ученым изысканиям» Общества музыкальных наук, «что первое время и не думал вступать в него» [11, 138-139]. Взгляды исследователей, недовольных попытками коллег приписать Баху стремление «поверить алгеброй гармонию», во многом подтверждаются свидетельствами современников Баха - например, его сына Филиппа Эммануэля: «Покойный был [...] не охотник до сухих математических материй» или И. Шайбе, будто бы слышавшего заявление Баха: «Музыканту достаточно заниматься своим искусством, а не сочинением толстых книг, и не тратить время на чтение ученых и философских исследований» $[4,33]$.

В романе Германа Гессе «Игра в бисер», пронизанном музыкой Баха - идентичная точка зрения представлена патером Иаковом. «Вы, касталийцы, - говорит он главному герою романа Иозефу Кнехту, - великие ученые и эстеты, вы измеряете вес гласных в старом стихотворении и соотносите его формулу с формулой орбиты какой-нибудь планеты. Это восхитительно, но это игра. Да ведь и ваши величайшие тайны и символ - тоже игра, игра в бисер...» $[1,154]$. Правда, постепенно Кнехт подводит патера «К признанию [...] и этого склада ума, и этого ордена, и этой попытки создать аристократию духа. Патер перестал [...] видеть в игре в бисер лишь эстетическое щегольство...» $[1,157]$.

А. Милка предлагает «тот тип барочного произведения, который мы обсуждаем и в котором используется развитая система вербальных, визуальных и звуковых символов [речь в его работе идет об «Искусстве фуги» Баха. - О. Э.] условно представить как специфическую систему уровней (или каналов) передачи информации:

1. прямой текст («один к одному»), который доступен всем, умеющим читать;

2. текст, который можно прочесть при помощи его дешифровки и который доступен тем, кто знает код;

3. текст, передаваемый при помощи тонкого и сложного ассоциативного аппарата и доступный лишь тем, кто обладает определенным запасом знаний, посвящен в данный круг проблем;

4. наконец, существует произведение как определенное единство, как целое, полный смысл которого доступен лишь тому, кто его создавал. Тем не менее приблизиться к его постижению возможно, и этому помогает постижение информации, которую несут все три предыдущих уровня» $[6,332]$.

Уточняя понятие музыкальности в ракурсе культурологическом и искусствоведческом, мы можем выявить тенденцию к вовлечению свойственных для восприятия музыкальных произведений механизмов в восприятие аудиторией текста литературного, т.е. стремление автора к максимально возможной степени синестетизма, и назвать этот процесс «музыкализацией».

Анализ конкретных художественных произведений позволил выделить следующие приемы «музыкализации»:

1. описание музыкальных произведений в литературном тексте;

2. использование традиционно «музыкальных» приемов для создания в произведении художественной литературы эффекта музыкальности:

- имитация специфически музыкальных эффектов, в частности придание словесному тексту музыкальной формы;

- использование лейтмотивов;

- «текучесть», преобладание слитности над структурностью, расчлененностью текста;

- «аккустизация» литературного текста, «звукопись», словесное моделирование музыкальной материи;

3. «союз» музыки и слова в практике создания оперного либретто на основе литературного произведения, положения стихотворений на музыку и др. 


\section{Учёные записки}

Комсомольского-на-Амуре государственного технического университета

Возможность «музыкализации» обеспечивается глубинными характеристиками музыки как древнейшего из искусств, воздействующими на человеческую психику, эмоциональность и психическое восприятие.

Стремление к синестетизму проявляется еще в эпохе барочного искусства - в музыкальной символике и музыкальной риторике И. С. Баха, служивших вербализации музыкального текста. «Знающему» слушателю инструментальные произведения Баха открывают конкретное образное, психологическое и философско-религиозное содержание, транслируют мысли, образы и сюжеты Священного Писания.

Однако только у Р. Вагнера тема синтеза искусств и синестетизма восприятия художественного произведения достигает высокого уровня теоретического обобщения. Концепт Вагнера Gesamtkunstwerk сыграл значительную роль в развитии немецкой музыки. Его основы, заложенные теоретическими трудами и практической деятельностью Р. Вагнера, в дальнейшем развивали, в частности, немецкие постромантики и представители Новой венской школы.

\section{ЛИТЕРАТУРА}

1. Гессе, Г. Игра в бисер. Опыт жизнеописания магистра Игры Иозефа Кнехта с приложением оставшихся от него сочинений / Г. Гессе // Собрание сочинений. В 8 т. Т. 5; пер. с нем. С. К. Апта. - М.: Прогресс - Литера; Харьков: Фолио, 1994. - 484 с.

2. Золотухина, О. Б. Эволюция психологизма Германа Гессе / О. Б. Золотухина. - Гродно: Гродненский государственный университет имени Янки Купалы, 2007. - 163 с.

3. Коляденко, Н. П. Синестетичность музыкально-художественного сознания: на материале искусства XX века: автореф. дис. ... д-ра искусствоведения / Коляденко Н.П. - Новосибирск, 2006. - 49 с.

4. Коростелев, В. Между Л. Мицлером и И. Маттезоном (Творческий процесс И. С. Баха и «музыкальная математика») / В. Коростелев // Южно-Российский музыкальный альманах. - 2013. - №1 (12). - С. 27-35.

5. Лосев, А. Ф. Философский комментарий к драмам Рихарда Вагнера / А. В. Лосев // Форма - Стиль - Выражение: сб.; сост. А. А. Тахо-Годи; общ. ред. А. А. Тахо-Годи и И. И. Маханькова; авт. послесл. В. В. Бычков и М. М. Гамаюнов. - М.: Мысль, 1995. - 944 с.

6. Милка, А. П. «Искусство фуги» И. С. Баха: к реконструкции и интерпретации / А. П. Милка. - СПб.: Композитор, 2009. - 456 с.

7. Носина, В. Б. Символика музыки И. С. Баха / В. Б. Носина. - Тамбов: Тамбов, 1993. - 104 с.

8. Носина, В. Б. Символика музыки И. С. Баха и ее интерпретация в «Хорошо темперированном клавире»/

В. Б. Носина. - М.: ГМПИ имени Гнесиных, 1991. -54 с.

9. Петров, Ю. Символика и диалектика чисел в «Хорошо темперированном клавире» И. С. Баха / Ю. Петров; Гос. муз.-пед. институт им. Гнесиных. - Минск: [б. и.], 1999. - 39 с.

10. Холопова, В. Н. Феномен музыки / В. Н. Холопова. - M.: Directmedia, 2014. - 279 с.

11. Швейцер, А. Иоганн Себастьян Бах / А. Швейцер. - М.: Музыка, 1965. - 728 с.

12. Элькан, О. Б. Gesamtkunstwerk Рихарда Вагнера: интеграция музыкальных и внемузыкальных художественных средств / О. Б. Элькан // Ученые записки Комсомольского-на-Амуре государственного технического университета. Науки о человеке, обществе и культуре. - 2017. - № III-2(31). - С. 85-90.

13. Яворский, Б. Л. Сюиты Баха для клавира / Б. Л. Яворский; под ред. С. Протопопова. - М. - Л., 1947. $156 \mathrm{c}$.

14. Liao, W.-Ch. A Study of Musical Rhetoric in J. S. Bach's Organ Fugues BWV 546, 552.2, 577, and 582 [Электронный ресурс] / W.-Ch. Liao. - University of Cincinnati, College-Conservator of Music. - 2015. - Режим доступа: https://oatd.org/oatd/record?record=oai\%5C\%3Aetd.ohiolink.edu\%5C\%3Aucin1427983542. 